\title{
Establishing links between uranium aqueous speciation and uptake by a unicellular alga
}

\author{
C. Fortin, L. Dutel and J. Garnier-Laplace
}

Institut de Protection et de Sûreté Nucléaire, DPRE, SERLAB, Laboratoire de Radioécologie Expérimentale, CE Cadarache, bâtiment 186, BP. 1, 13108 Saint-Paul-lez-Durance, France

\begin{abstract}
The bioavailability and toxicity of dissolved metals are closely linked to the metals' chemical speciation in solution. Normally the complexation of a metal by a ligand would be expected to decrease its bioavailability. The aqueous speciation of uranium undergoes tremendous changes within a $\mathrm{pH}$ range of 4 to 8 and in the presence of ligands commonly found in natural waters (carbonate, phosphate, hydroxide and natural organic matter). In the present project, we intend to establish links between speciation, medium composition and bioavailability of uranium. To study these links, we have chosen a unicellular green alga. Short-term metal uptake rates are determined in simple inorganic media with particular emphasis on the differentiation between adsorbed and intracellular metal. The Free-Ion Model (FIM) is tested to determine if U uptake is governed by the free uranyl species $\left(\mathrm{UO}_{2}{ }^{2+}\right)$ or if other species can be assimilated (i.e. passive diffusion of neutral, presumably lipophilic, species such as $\mathrm{UO}_{2}(\mathrm{OH})_{2}$; facilitated diffusion of metal bound to an assimilable ligand such as uranium-phosphate complexes). Results of our preliminary experiments indicate that complexation by phosphate decreases uranium bioavailability, as predicted by the FIM. However, uptake was stimulated when pH was increased from 5 to 7 in spite of the substantial decrease $(55 \rightarrow 0.02 \%)$ in free uranyl ion concentration in solution.
\end{abstract}

\section{INTRODUCTION}

It is generally accepted that the total aqueous concentration of a metal is not a good predictor of its $<$ bioavailability>, i.e. the metal's speciation will affect its availability to aquatic organisms. Qualitatively, complexation of a metal normally leads to a decrease in its bioavailability. In effect, most dissolved ligands (both inorganic and organic) that bind metals form hydrophilic complexes, $\mathrm{ML}_{\mathbf{n}}{ }^{ \pm}$. In such systems metal uptake, nutrition and toxicity normally vary as a function of the concentration of the free-metal ion in solution; this relationship is known as the Free-Ion-Model (FIM) [1]. However, a number of intriguing experiments have been reported in the literature where the metal's "residual" bioavailability in the presence of hydrophilic $\mathrm{ML}_{\mathrm{n}}{ }^{ \pm}$complexes has been found to exceed that which would have been predicted on the basis of the free-metal ion concentration at equilibrium [2]. Such intriguing results have been reported for $U$ toxicity (valve movement response) toward the bivalve, Velesunio angasi, in laboratory exposure experiments [3]. Increasing $\mathrm{pH}$ from 5.0 to 6.0 decreased uranium toxicity, however, this amelioration could not be solely related to the decrease in $\left\{\mathrm{UO}_{2}{ }^{2+}\right\}$ within this range. The authors concluded that the first hydrolysis product of uranyl $\left(\mathrm{UO}_{2} \mathrm{OH}^{+}\right)$could be the culprit. In another toxicity study using the green alga Chlorella vulgaris, it was found that increasing $\mathrm{pH}$ from 5.7 to 6.5 worsen $\mathrm{U}$ toxicity (EC50 from growth inhibition bioassays of $328 \mathrm{nM}$ down to $185 \mathrm{nM} \mathrm{U}$ ) [4]. One of our objectives is to test the applicability of the FIM to uranium uptake using a unicellular alga as our biological model in the presence of inorganic (e.g. phosphate) and organic (e.g. natural organic matter) ligands.

Most of these apparent exceptions to the FIM of metal toxicity involve organic ligands that are assimilable in their own right (e.g. low molecular weight metabolites), and this has led to the suggestion that "accidental" metal transport may occur in their presence (i.e., the ligand is assimilated as a metalligand complex and the metal "comes along for the ride") [2]. In principle, the assimilation of intact hydrophilic metal-ligand complexes could also occur with inorganic ligands such as phosphate. Uptake systems for such essential nutrient anions exist at biological interfaces; if these transport systems could be "fooled" into binding and transporting the intact metal-anion complex, then the metal would find its way into the cell "accidentally". The binding of the U by phosphate $\left(\mathrm{UO}_{2}{ }^{2+}+\mathrm{HPO}_{4}{ }^{2-} \leftrightarrow \mathrm{UO}_{2} \mathrm{HPO}_{4}{ }^{0}: \log \mathrm{K}=\right.$ 
7.24) will reduce the free $\mathrm{UO}_{2}{ }^{2+}$ concentration and thus, according to the FIM, should reduce uranium bioavailability. We postulated that uranium could cross biological membranes as the uranium-phosphate complex, via an anion transporter, and set out to test this "molecular mimicry" hypothesis [5, 6]. Since algae are known to possess membrane-bound transport systems for the assimilation of phosphate, they should be appropriate models for testing the hypothesis that uranium-phosphate complexes can mimic phosphate and enter the cells via the same pathway.

\section{METHODS}

The experiments were carried out with a euryhaline unicellular green alga, Chlamydomonas reinhardii, in defined inorganic media. Cells were grown axenically in $100 \mathrm{~mL}$ of modified high salt medium with an ionic strength of $10 \mathrm{meq} \cdot \mathrm{L}^{-1}$ [7]. Uranium uptake experiments were done with the ${ }^{233} \mathrm{U}$ radioisotope (83 $\mathrm{kBq} \cdot \mu \mathrm{mol}^{-1}$ as uranyl nitrate, CERCA Framatome). For each experiment, cells were initially inoculated at a density of 2,500 cells $\cdot \mathrm{mL}^{-1}$, allowed to grow for $48 \mathrm{~h}$ at $20 \pm 1{ }^{\circ} \mathrm{C}$ under constant illumination $(90 \pm 10$ $\mu \mathrm{mol} \cdot \mathrm{m}^{-2} \cdot \mathrm{s}^{-1}$ ) to reach mid-exponential growth and then gently harvested on a $2-\mu \mathrm{m}$ polycarbonate filter membrane (Poretics) using a vacuum pressure of $\leq 10 \mathrm{~cm} \mathrm{Hg}$. Harvested cells were rinsed five times with $5 \mathrm{~mL}$ of sterile simplified culture medium containing neither phosphate nor trace metals, and then resuspended in $<5 \mathrm{~mL}$ of the same simplified medium. Size distribution, average surface area and density were rapidly determined using a Coulter Z2 particle counter ( $100 \mu \mathrm{m}$ orifice tube) and recorded. Cells were then exposed under the conditions outlined below for a short period of time ( $\leq 60 \mathrm{~min})$. Short exposure times were used to avoid release by the algal cells of metal-binding peptides that could affect uranium speciation in solution, and to minimise cell division that would increase cell density during the exposure. Experiments were conducted under ambient laboratory conditions and with low cell numbers $\left(-50,000 \mathrm{cells} \cdot \mathrm{mL}^{-1}\right)$, to minimise metal depletion through uptake and adsorption by the algal cells (e.g., minimal decrease in dissolved uranium concentration, $<5 \%$ after 60 minutes). Finally, cells were recovered on two superimposed filter membranes. The activity of the lower membrane was subtracted from the activity of the upper one to eliminate interference from uranium adsorption on the filter. Loosely bound ${ }^{233} \mathrm{U}$ was removed from the algal surface by rinsing $(5 \times 5 \mathrm{~mL})$ with a simplified culture medium + $50 \mu \mathrm{M}$ EDTA solution (operationally defined as the intracellular uranium fraction). The adsorbed fraction of uranium was calculated from the total measurement (no rinse) and intracellular content (EDTA rinse). Cells were acid-digested with concentrated $\mathrm{HNO}_{3}$ and ${ }^{233} \mathrm{U}$ activities were measured by liquid scintillation counting using a low-background spectrometer (Quantulus 1220). All uptake experiments were performed at a $\mathrm{pH}$ of either 5 or 7 without any buffers, with a minimum of three replicates and uptake values were then normalised for the total algal surface area. Uranium speciation in the exposure solutions was calculated with the chemical speciation model MINEQL+ v4.06 with an updated thermodynamic data base prepared from reliable sources of thermodynamic data $[8,9]$.

\subsection{Experimental conditions}

\subsubsection{Uptake kinetics}

In this first experiment, both uranium adsorption and absorption were measured after $0,15,30,45$ and 60 min of exposure to a total ${ }^{233} \mathrm{U}$ concentration of $200 \mathrm{nM}$ at a $\mathrm{pH}$ of 5 . The objective was to verify that uptake was linear on a short time scale. We expected adsorption to reach a rapid steady state whereas absorption would steadily increase over the 60-min time frame. A "time-zero" measurement was included to evaluate the efficiency of the EDTA rinse to remove surface bound uranium (i.e. assuming very fast surface binding and slow absorption, the uptake curve should go through the origin).

\subsubsection{Concentration dependence of uranium uptake}

In this second experiment, both the adsorbed and intracellular fractions were measured at increasing total uranium concentrations $\left(20,100,200,500,1000\right.$ and $\left.2000 \mathrm{nM}^{233} \mathrm{U}\right)$ at $\mathrm{pH} 5$ and 7 for a fixed exposure time of $30 \mathrm{~min}$. A relatively broad range of uranium concentration was used in order to (potentially) observe a saturation of trans-membrane transport. Membrane transport of an ion usually follows the 
classic Michaelis-Menten enzymatic kinetics model. The half-saturation constant, $\mathrm{K}_{\mathrm{m}}$, and maximum uptake, $\mathrm{V}_{\max }$, may be derived from this data and compared as a function of $\mathrm{pH}$.

\subsubsection{Influence of phosphate on uranium bioavailability}

To determine the impact of phosphate on uranium uptake, this experiment was carried out at $\mathrm{pH} 5$ to minimise the presence of hydroxo-complexes and designed to hold a constant free uranyl ion concentration by increasing concomitantly both phosphate and total uranium concentrations (Table 1). The range of phosphate concentrations (up to $50 \mu \mathrm{M}$ ) used was selected to induce a significant change in aqueous uranium speciation while being within environmentally relevant concentrations; eutrophic streams can have $P$ concentrations exceeding the highest total phosphorus guidelines from either the US EPA (3.2 $\mu \mathrm{M}$ in streams that do not discharge directly into lakes or reservoirs) or the UK Environment Agency $(6.5 \mu \mathrm{M}$ in running eutrophic fresh waters).

Table 1: Exposure conditions and calculated species distribution for the uranium - phosphate uptake experiment.

\begin{tabular}{cccccccc} 
Medium & $\begin{array}{c}{[\mathrm{U}]_{\mathrm{T}}} \\
(\mathrm{nM})\end{array}$ & $\begin{array}{c}{\left[\mathrm{PO}_{4}{ }^{3-}\right]_{\mathrm{T}}} \\
(\mu \mathrm{M})\end{array}$ & $\begin{array}{c}{\left[\mathrm{UO}_{2}{ }^{2+}\right]} \\
(\mathrm{nM})\end{array}$ & $\begin{array}{c}{\left[\mathrm{UO}_{2} \mathrm{HPO}_{4}{ }^{0}\right]} \\
(\mathrm{nM})\end{array}$ & $\begin{array}{c}{\left[\mathrm{UO}_{2} \mathrm{PO}_{4}{ }^{-}\right]} \\
(\mathrm{nM})\end{array}$ & $\begin{array}{c}{\left[\mathrm{UO}_{2} \mathrm{OH}^{+}\right]} \\
(\mathrm{nM})\end{array}$ & $\begin{array}{c}{\left[\mathrm{UO}_{2}(\mathrm{OH})_{2}{ }^{0}\right]} \\
(\mathrm{nM})\end{array}$ \\
\hline $\mathrm{A}$ & 187 & 0 & 100 & 0 & 0 & 46 & 33 \\
$\mathrm{~B}$ & 255 & 10 & 100 & 64 & 3 & 46 & 33 \\
$\mathrm{C}$ & 391 & 30 & 100 & 191 & 9 & 46 & 33 \\
$\mathrm{D}$ & 527 & 50 & 100 & 306 & 15 & 46 & 33
\end{tabular}

\subsubsection{Intracellular distribution}

Intracellular distribution of uranium within the algal cells was estimated by disrupting the plasma membrane using an ultrasonic probe. Cells were sonicated for six minutes $(60 \mathrm{~W}$; pulsed for 6 sec every 7 $\mathrm{sec}$ ) in simplified culture medium containing $50 \mu \mathrm{M}$ EDTA. The distupted cells were then centrifuged at $100000 \mathrm{~g}$ for $30 \mathrm{~min}$ at $15^{\circ} \mathrm{C}$ to separate the insoluble fraction (pellet) from the cytosol (supernatant).

\section{RESULTS AND DISCUSSION}

\subsection{Kinetics of uranium uptake and adsorption}

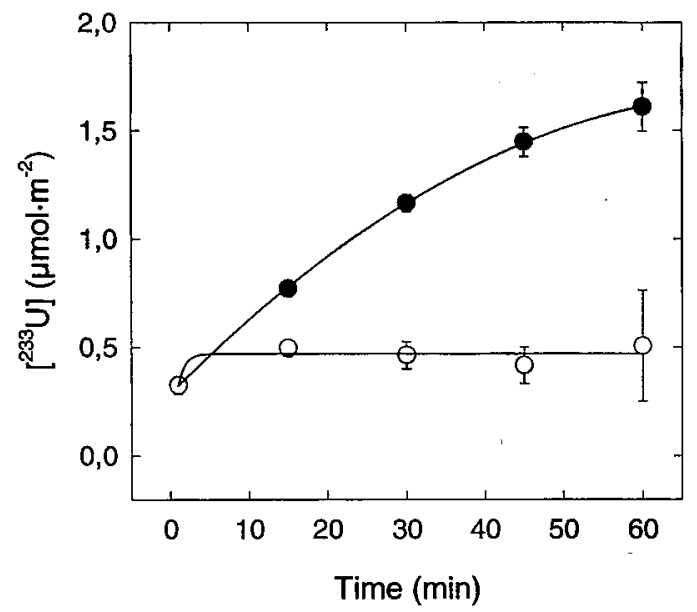

Figure 1: Time-dependence of uranium uptake at a total concentration of $200 \mathrm{nM}(\bullet=$ intracellular; $\circ=$ extracellular $)$. Error bars represent the standard deviation from the average of three measurements. 
Rapid and quasi-linear intracellular uranium uptake was observed over the 60 -min incubation period (Figure 1). Thus, for fixed exposure time experiments, a 30 -min contact time was chosen to get a sufficient radioisotope activity for scintillation counting while working within the linear domain of metal accumulation. For the zero-time $(\mathrm{t} \sim 1 \mathrm{~min})$ control, uranium uptake was significantly different than zero $\left(0.33 \pm 0.01 \mu \mathrm{mol} \cdot \mathrm{m}^{-2}\right)$, indicating that part of the surface bound metal is not removed by the EDTA wash. The EDTA concentration $(50 \mu \mathrm{M})$ was selected to both maximise uranium complexation $(\log \mathrm{K}$ $\mathrm{UO}_{2}$ HEDTA $^{-}=19.76$ ) and minimise $\mathrm{Ca} / \mathrm{Mg}$ complexation which could affect ionic regulation and membrane permeability. Increasing EDTA wash concentration 10 -fold to $500 \mu \mathrm{M}$ significantly reduced the operationally defined intracellular $U$ uptake concentration after a 30 -min exposure to $180 \mathrm{nM}{ }^{233} \mathrm{U}$ from $0.52 \pm 0.07$ to $0.35 \pm 0.07 \mu \mathrm{mol} \cdot \mathrm{m}^{-2}$. Increasing EDTA concentration from 50 to $500 \mu \mathrm{M}$ thus resulted in the desorption of an extra $0.17 \mu \mathrm{mol} \cdot \mathrm{m}^{-2}{ }^{233} \mathrm{U}$. This, however, only represents half of the measured zero-time accumulation and hence cannot explain this deviation of the uptake curve from the origin. It seems that part of the adsorbed uranium is very strongly bound to the surface (possibly irreversibly) and further experimentation will be required to investigate this phenomenon.

As opposed to absorption, adsorption reaches a steady-state very rapidly, apparently within the first minutes of contact with uranium (Figure 1). Uranium thus behaves similarly to other trace metals such as $\mathrm{Cu}, \mathrm{Ni}, \mathrm{Mn}$ and $\mathrm{Zn}$ with regards to adsorption to algal surfaces [10-13].

\subsection{Concentration dependence of uranium uptake and adsorption}

Uranium cellular uptake was up to $3.3 \mathrm{X}$ greater at $\mathrm{pH} 7$ than at $\mathrm{pH} 5$ (Figure 2a). Typically, metal accumulation increases with $\mathrm{pH}$ due to a decrease in competitive binding to transport sites between the hydronium ions and the metal ions $[11,14]$. However, uranium speciation undergoes tremendous changes within the $\mathrm{pH}$ range tested; the free uranyl ion concentration is more than three orders of magnitude lower at $\mathrm{pH} 7$ than at $\mathrm{pH} 5$ according to equilibrium thermodynamic calculations. Thus, it could be argued that the decrease in uranyl ion activity was overcompensated by the decrease in hydronium ion competition. Yet, the $\mathrm{H}_{3} \mathrm{O}^{+}$activity varies only by two orders of magnitude, which would indicate that $\mathrm{H}^{+}$has a higher affinity than $\mathrm{UO}_{2}{ }^{2+}$ for the transport binding sites. This is highly unlikely and leads us to believe that uranium uptake does not comply to the FIM of metal bioavailability.
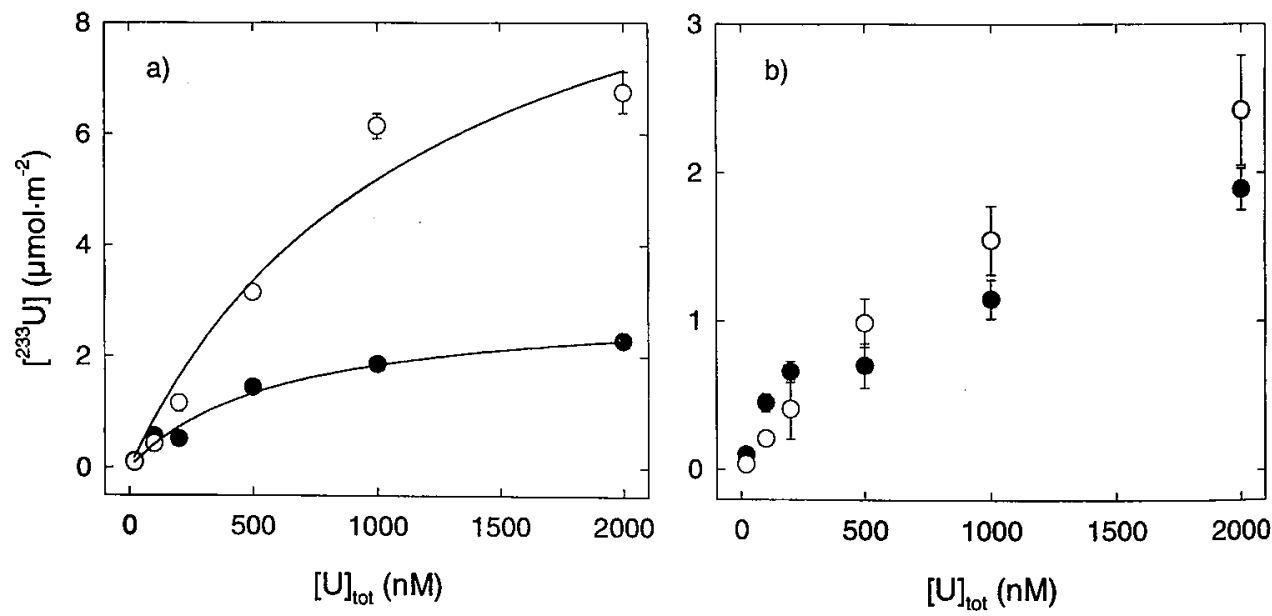

Figure 2: Utanium uptake after 30 minutes of exposure at various total uranium concentrations a) Intracellular uptake. b) Extracellular adsorption $(\bullet=\mathrm{pH} 5 ; 0=\mathrm{pH} 7)$. Error bars represent the standard deviation from the average of three measurements.

More than one transport mechanism (facilitated diffusion of the free uranyl ion) might contribute to uranium intake: i) The facilitated diffusion of hydroxo-complexes [15]; or ii) The passive diffusion of neutral lipophilic complexes such as $\mathrm{UO}_{2}(\mathrm{OH})_{2}{ }^{0}$ (e.g. analogue to $\mathrm{HgCl}_{2}{ }^{0}$ movement across membranes 
[16]). Both mechanisms can be considered as plausible explanations. No data is available in the literature on the relative lipophilicity of the dihydroxo-complex of uranyl (e.g. octanol-water partition coefficients, $\mathrm{K}_{\mathrm{OW}}$, this approach could complement uranium uptake experiments). The uptake pattern at pH 7 (Figure $2 \mathrm{a}$; open symbols) is linear up to $1 \mu \mathrm{M}$ uranium and could point toward a non-saturable passive diffusion process. A plateau seems to be reached at $2 \mu \mathrm{M}$ but this should be confirmed at higher concentrations in order to conclude.

Nonetheless, Michaelis-Menten kinetic parameters $K_{m}$ and $V_{\max }$ were determined using the Marquardt-Levenberg algorithm to obtain the best fit to the observed uptake levels (Table 2; see also curves in Figure 2a). The half-saturation constant is nearly doubled at $\mathrm{pH} 7$ when the data is analysed based on the total uranium concentrations. Using the calculated free uranyl ion concentrations, the difference in the $\mathrm{K}_{\mathrm{m}}$ becomes very large $(\sim 800 \mathrm{X}$ greater at $\mathrm{pH} 5)$ due to the pronounced uranium complexation at $\mathrm{pH} 7$. It is doubtful that the characteristics of an ion transporter could undergo such a major change. The internalisation mechanism of uranium is still unknown and its identification would help understand the accumulation patterns. Nevertheless, one the FIM underlying assumptions might not be respected.

Table 2: Michaelis-Menten model parameters describing uranium uptake by the alga based on either the total uranium or the free uranyl ion concentration.

\begin{tabular}{c|ccc|ccc}
$\mathrm{pH}$ & $\mathrm{K}_{\mathrm{m}}\left(\mathrm{nM} \mathrm{U}_{\text {tot }}\right)$ & $\mathrm{V}_{\max }\left(\mu \mathrm{mol} \cdot \mathrm{m}^{-2} \cdot \mathrm{min}^{-1}\right)$ & $\mathrm{r}^{2}$ & $\mathrm{~K}_{\mathrm{m}}\left(\mathrm{nM} \mathrm{UO}_{2}{ }^{2+}\right)$ & $\mathrm{V}_{\max }\left(\mu \mathrm{mol} \cdot \mathrm{m}^{-2} \cdot \mathrm{min}^{-1}\right)$ & $\mathrm{r}^{2}$ \\
\hline 5.0 & 630 & 0.101 & 0.99 & 340 & 0.102 & 0.98 \\
7.0 & 1220 & 0.383 & 0.96 & 0.42 & 0.480 & 0.96
\end{tabular}

Adsorption to the cell surface remains unsaturated throughout the concentration range tested, although a slight curvature can be noticed. As opposed to intracellular intake, adsorption levels remain virtually unaffected by the $\mathrm{pH}$, indicating very little competition with the hydronium ion for the external binding sites within the range of 5 to 7 .

These levels of uranium adsorption and absorption are within an order of magnitude of those observed by Franklin et al. [4]. These authors had also obtained higher absorption of uranium with $\mathrm{pH}$ $(5.7 \rightarrow 6.5)$. On the other hand, there was a 4-fold increase in adsorption whereas we did not observe much change on a larger $\mathrm{pH}$ scale. This discrepancy between the two studies is most likely due to the difference in exposure times ( $30 \mathrm{~min} v s .72 \mathrm{hrs}$ ). Although adsorption is constant over one hour (Figure 1; open symbols), extrapolation to longer periods might be hazardous. Such long exposure periods, at the concentrations tested ( $170-1050 \mathrm{nM} \mathrm{U} ; 72$-h EC50s in the range of $185-328 \mathrm{nM})$ by the authors, most probably induced toxic effects (e.g. cell lysis) which may have modified adsorption patterns.

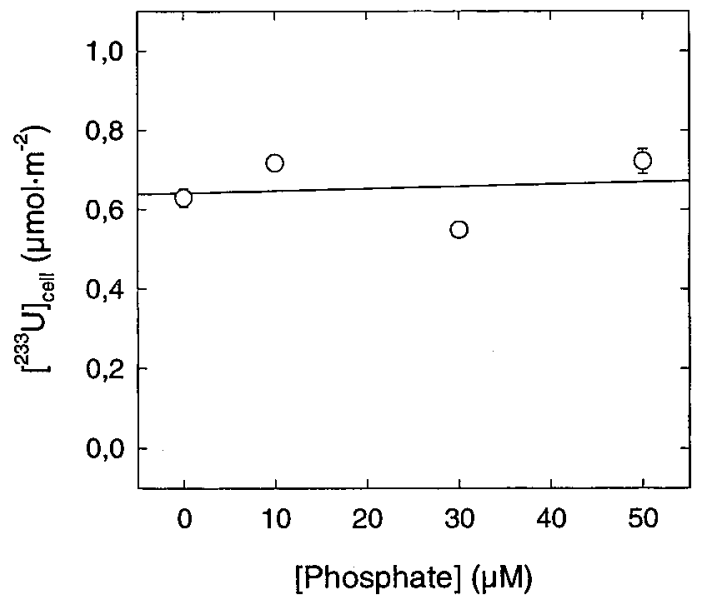

Figure 3: Intracellular uranium content observed after a 30-min exposure at $\mathrm{pH} 5$ with increasing uranium and phosphate concentrations to maintain a constant free uranyl ion concentration of $100 \mathrm{nM}$. Error bars represent the standard deviation from the average of three measurements. 


\subsection{Test of the free-ion model: Influence of phosphate on uranium uptake}

The presence of phosphato-complexes of uranium up to $330 \mathrm{nM}$ (calculated concentrations of $\mathrm{UO}_{2} \mathrm{PO}_{4}$, $\mathrm{UO}_{2} \mathrm{HPO}_{4}{ }^{0}$ and $\mathrm{UO}_{2} \mathrm{H}_{2} \mathrm{PO}_{4}{ }^{+}$; representing up to $62 \%$ of total uranium) did not induce a trend in uranium uptake by the alga (Figure 3 ). For a constant free uranyl ion concentration of $100 \mathrm{nM}$, uptake remained unaffected as would have predicted the FIM. We can thus conclude that uranium complexation by phosphate at environmentally relevant concentrations reduces the uranium bioavailability and that uranium - phosphate complexes do not contribute significantly to the uptake of this metal.

\subsection{Intracellular distribution of uranium}

Measurements of ${ }^{233} \mathrm{U}$ within the soluble (cytosol) and insoluble fractions (vacuoles, nuclei, flagella, membranes) obtained after sonication revealed that a high proportion $(\sim 75 \%)$ of the uranium was located in the latter. Only about $25 \%$ of the ${ }^{233} \mathrm{U}$ accumulated over $30 \mathrm{~min}$ at $\mathrm{pH} 5$ was found in the cytosol. This might indicate that uranium could be rapidly "stored" within the alga. On the other hand, this could be due to the presence of non-exchangeable uranium bound to the plasma membrane.

\section{CONCLUSION}

The prevailing paradigm for metal uptake by aquatic organisms, i.e. the Free Ion Model or its derivative the Biotic Ligand Model, assumes that metals enter living cells via facilitated cation transport. Most known exceptions to the FIM involve either ligands that form lipophilic complexes, $\mathrm{M}_{-} \mathrm{L}_{n}{ }^{\circ}$, which can bypass normal metal transport mechanisms and cross biological membranes by simple diffusion. Such an exception could apply to uranium at circumneutral $\mathrm{pH}$ where the neutral second hydrolysis product of uranyl dominates aqueous U(VI) speciation. However, facilitated transport of the cationic $\mathrm{UO}_{2} \mathrm{OH}^{+}$ complex cannot be excluded at this time as an explanation of the stimulated uptake observed when increasing $\mathrm{pH}$ from 5 to 7 . On the other hand, no evidence of metal uptake through anion transport systems was observed in the presence of phosphate.

\section{References}

[1] Morel F.M.M. and Hering J.G., Principles and Applications of Aquatic Chemistry. (John Wiley \& Sons, New York, 1993).

[2] Campbell P.G.C., Metal Speciation and Bioavailability in Aquatic Systems (John Wiley \& Sons, New York, 1995) pp 45-102.

[3] Markich S.J., Brown P.L. and Jeffree R.A., Radiochim. Acta 74 (1996) 321-326.

[4] Franklin N.M., Stauber J.L., Markich S.J. and Lim R.P., Aquat. Toxicol. 48 (2000) 275-289.

[5] Clarkson T.W., Ann. Rev. Pharmacol. Toxicol. 32 (1993) 545-571.

[6] Fortin C. and Campbell P.G.C., Environ. Sci. Technol. 35 (2001) 2214-2218.

[7] Fortin C. and Campbell P.G.C., Environ. Toxicol. Chem. 19 (2000) 2769-2778.

[8] Martell A.E., Smith R.M. and Motekaitis R.J., NIST Standard Reference Database 46. (U.S. Dept. of Commerce, Gaithersburg, MD, 1998).

[9] Östhols E. and Wanner H., The NEA thermochemical data base project. (Nuclear Energy Agency, France, 2000).

[10] Bates S.S., Tessier A., Campbell P.G.C. and Buffle J., J. Phycol. 18 (1982) 521-529.

[11] Schenck R.C., Tessier A. and Campbell P.G.C., Limnol. Oceanogr. 33 (1988) 538-550.

[12] Knauer K., Behra R. and Sigg L., J. Phycol. 33 (1997) 596-601.

[13] Mehta S.K., Tripathi B.N. and Gaur J.P., Eur. J. Protistol. 36 (2000) 443-450.

[14] Harrison G.I., Campbell P.G.C. and Tessier A., Can. J. Fish. Aquat. Sci. 43 (1986) 687-693.

[15] Markich S.J., Brown P.L., Jeffree R.A. and Lim R.P., Aquat. Toxicol. 51 (2000) 155-175.

[16] Mason R.P., Reinfelder J.R. and Morel F.M.M., Environ Sci Technol 30 (1996) 1835-1845. 